\title{
FURTHER NOTES ON THE HABITS OF
}

\author{
HARPAGOXENUS AMERICANUS. ${ }^{1}$
}

By Wm. S. Creighton

The social parasitism of Harpagoxenus americanus, Em., has been discussed by Sturtevant in a paper published in 1927. This investigator found that the behavior of an artificially deälated Harpagoxenus female placed in a nest of Leptothorax curvispinosus, one of its natural hosts, agrees in all essential respects with that of the females of the sanguinea group in Formica. The strange queen is at once attacked by the Leptothorax workers but she eventually cripples most of her assailants, disorganizes the remainder and takes possession of the brood.

During the summer of 1928 I was stationed on Naushon Island (Woods Hole), Mass., the only place in New England where Harpagoxenus is known to be at all plentiful. I was fortunate in securing several mixed colonies and in rearing from one of these numerous males and females. There was consequently abundant opportunity to repeat the experiment previously made by Sturtevant. Our results differ only in minor details which may be due to the fact that he used L. curvispinosus as the host while I employed L. longispinosus. Sturtevant introduced his deälated Harpagoxenus female into a nest containing seventy workers of $L$. curvispinosus and secured good results. I found it necessary to strip the host nest of all but about fifteen workers in order to prevent the death of the Harpagoxenus queen. If a larger number of longispinosus workers were present they invariably pulled down and killed the intruder by force of numbers. The worker of longispinosus is slightly larger than that of curvispinosus and its greater size may give it an advantage in attacking the invader. It was also necessary to wait for one hour after deälating the Harpagoxenus female before placing it in the nest of the host. If placed therein immediately after deäla-

1Contributions from the Entomological Laboratory of the Bussey Institution, Harvard University, No. 311. 
tion it behaved in a most apathetic manner and was quickly dispatched by the Leptothorax workers before it showed any signs of pugnacity. Since the wings are very easily removed it does not seem probable that this initial quiescence can be due to the shock of the operation. A more likely explanation appears to be that the high degree of excitability so characteristic of the actions of many of the queens of the social parasites is in some way connected with the degeneration of the wing muscles. Such a process would require an appreciable lapse of time before it could become effective.

The results of nine experiments in which an artificially deälated Harpagoxenus female was introduced into a nest of Leptothorax longispinosusis may be summed up as follows:

The strange queen almost immediately approaches the brood and is at once attacked by the Leptothorax workers. She defends herself with extreme ferocity, biting off the antennae and legs of her assailants with quick, jerky movements and giving them little opportunity to seize her. Whenever possible the Harpagoxenus queen returns to the brood and drives away the Leptothorax workers who are moving the larvæ and pupæ. Her bursts of savageness are sometimes interspersed with periods of apathy during which she remains completely inactive and allows the Leptothorax workers to drag her about the nest. Eventually she maims or kills all the Leptothorax workers and takes possession of the brood. The Leptothorax queen is seldom attacked, since she avoids the intruder, but usually dies at the end of a few days, apparently from starvation. It is interesting to note that the Leptothorax callows very rarely show animosity or fear for the Harpagoxenus queen and are never molested by it.

In addition to the experiments with deälated females a few observations were made on Harpagoxenus brood. One mixed nest which was taken on June 15 contained a large number of larvæ, most of which subsequently proved to be Harpagoxenus. The length of the larval period could not be determined but the pupal period of the males and females is from twenty-three to twenty-five days. That of the worker is a day or two longer. There is no callow period for either worker or sexual forms. All are deeply colored at the time of emergence. 
On Aug. 4, at 3:30 p.m. I witnessed a raid of Harpagoxenus and subsequently saw several others from the same nest. The raids differed in only one respect from those which I described in a previous paper ('27). The tendency of the raiders to move in columns, which I saw only once during former observations, was a regular feature of these raids. There were never more than six ants in a column. They moved in single file and kept quite close together. Their antennæ were rapidly vibrated and constantly brought in contact with the substratum or the ant ahead.

It may be of interest to note that Harpagoxenus americanus is now known to occur as far north as Boston, Mass. In the spring of 1927 I took a single female in the Blue Hills Reservation. The nest was small and contained, beside the queen eleven workers of $L$. longispinosus and a small amount of brood. No Harpagoxenus workers were present. The known range extends from Massachusetts through southern New York, New Jersey and eastern Pennsylvania as far south as Washington. It is likely that in the future our knowledge of its southern range will be considerably extended but the scarcity of the insect in Massachusetts points to this state as the northern limit of its distribution.

Creighton, W. S.

Literature cited:

1927. The Slave-Raids of Harpagoxenus americanus. Psyche, Vol. 34, p. 11-29.

Sturtevant, A. H.

1927. The Social Parasitism of the Ant Harpagoxenus americanus. Ibidem, p. 1-9. 

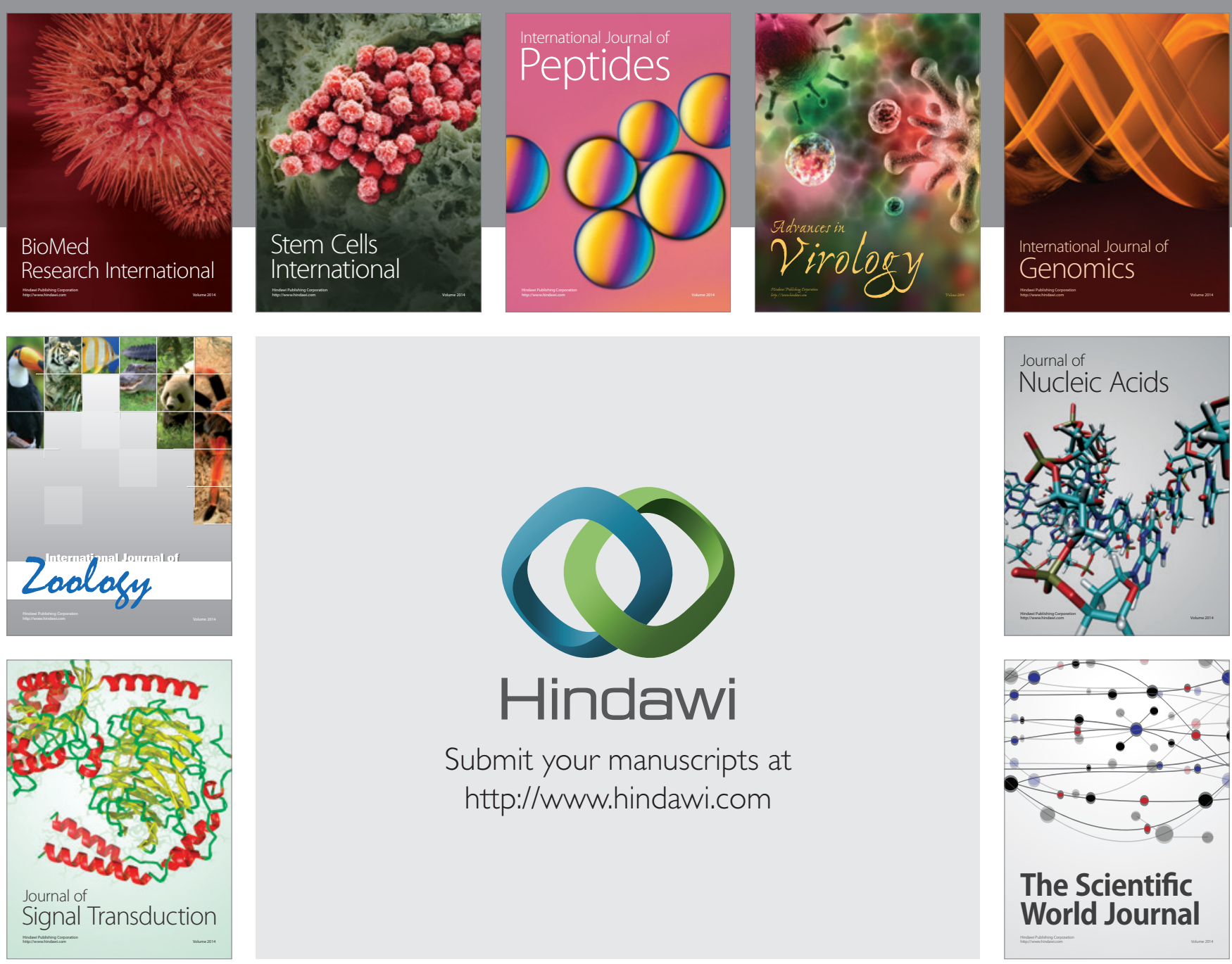

Submit your manuscripts at

http://www.hindawi.com
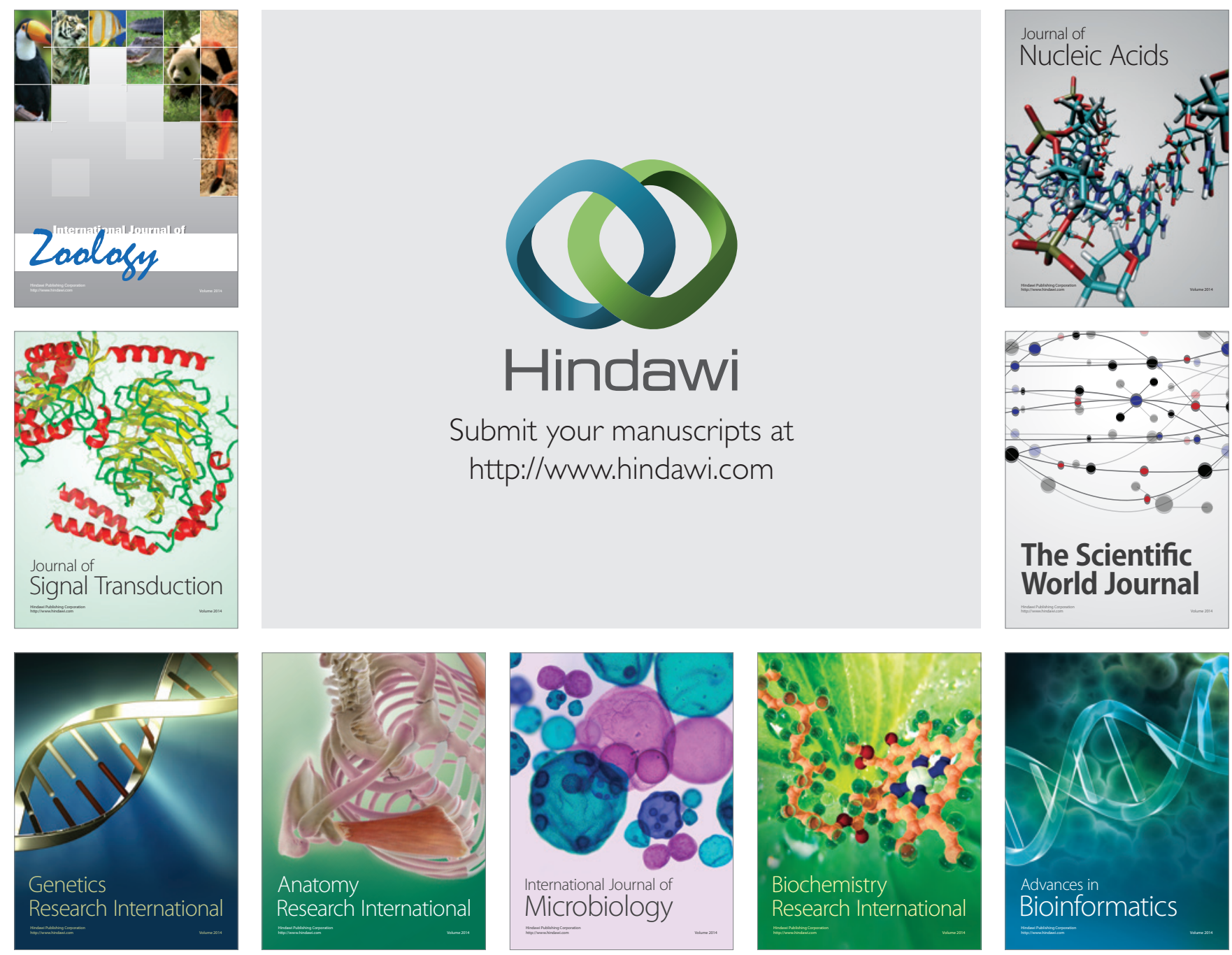

The Scientific World Journal
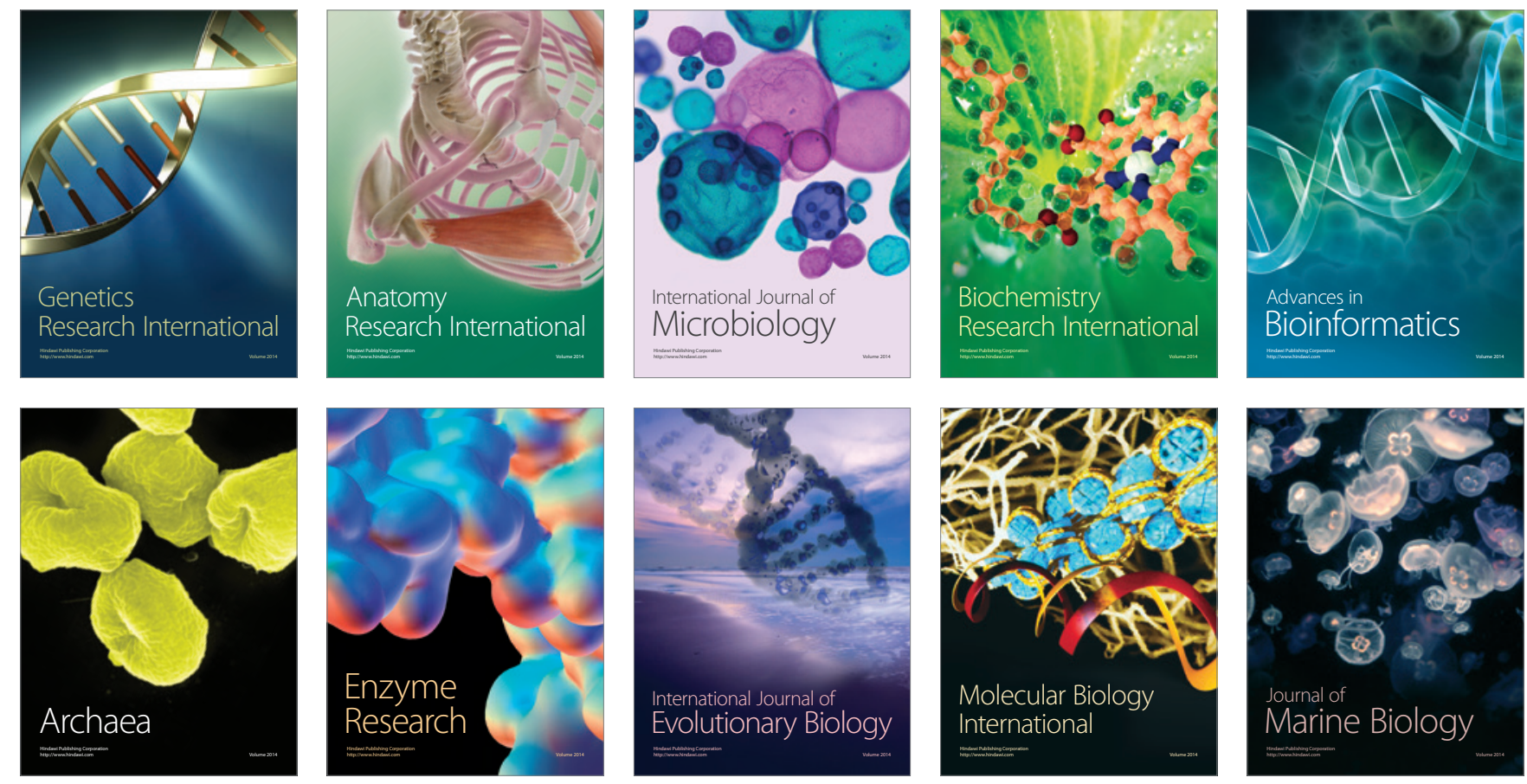